\title{
From Nernst to Bernstein and Beyond
}

\author{
Bernard Delalandeㄹ, Hirohisa Tamagawa², Vladimir Matveev ${ }^{3}$ \\ ${ }^{1}$ NeuroDynamique.fr, La Verpilliere, France \\ ${ }^{2}$ Department of Mechanical Engineering, Faculty of Engineering, Gifu University, Gifu, Japan \\ ${ }^{3}$ Laboratory of Cell Physiology, Institute of Cytology, Russian Academy of Sciences, St. Petersburg, Russia \\ Email: bernard@somasimple.com
}

How to cite this paper: Delalande, B., Tamagawa, H. and Matveev, V. (2020) From Nernst to Bernstein and Beyond. Open Access Library Journal, 7: e7047. https://doi.org/10.4236/oalib.1107047

Received: November 27, 2020

Accepted: December 22, 2020

Published: December 25, 2020

Copyright $\odot 2020$ by author(s) and Open Access Library Inc.

This work is licensed under the Creative Commons Attribution International License (CC BY 4.0).

http://creativecommons.org/licenses/by/4.0/ (c) (i) Open Access

\begin{abstract}
Man has always been interested in animal electricity, which seems to be measured in every living cell. He has been fascinated by trying to elucidate the mechanisms by which this potential is created and maintained. Biology is the science that seeks to explain this mystery. Biology is based on basic sciences such as physics or chemistry. The latter, in turn, make systematic use of mathematics to measure, evaluate and predict certain phenomena and to develop "laws" and models that are as general as possible while respecting, as closely as possible, observations and facts. The Nernst equation was one of the pillars of electrochemistry. Biology also uses this same equation as one of the indispensable bases for the computation of membrane potential. Man has established a cellular model that highlights this equation in several forms. However, we are going to show by various means that this model is inadequate or even inapplicable.
\end{abstract}

\section{Subject Areas}

Biophysics, Neuroscience

\section{Keywords}

Bernstein, Nernst, Hodgkin \& Huxley Model, Biology, Biophysics

\section{Introduction}

To improve the understanding and interest of the reader, the authors decided to bring an innovative form of storytelling to the writing of the article. We stage protagonists gathered to discuss a topic. Our "actors" are of course scientists...

Three friends decided, at a night out, to change the world. Well, a ridiculously small part of the world. Walt is a physicist. His friend Jules is a biologist. Guy is the last comrade. He's a philosopher who likes to play devil's advocate between 
the two scientists. It is often he who decides the controversial subject.

The subject of the evening is the following: "The exchanges between Galvani and Volta remain famous, yet the first plausible theory concerning the membrane potential was that of Bernstein. Is the model and its evolution still relevant today, or should modifications be made, or a new building be made?"

Controversy can by no means exclude the production of arguments. Nor should it prevent us from keeping an open mind during the discussion. Participants make appropriate use of references to support their claims and are encouraged to keep a critical, curious and logical mind.

\section{Materials and Methods}

\subsection{Model Construction}

Walt is the first to respond.

-If a model must, as usual, be close to the observations and in no way change the way the observed thing works then I can easily say that this model is very bad for several reasons.

-You're pushing it a bit hard, Walt!

-You know well, Jules, that our friend Walt will try to defend his point of view; he won't fail to give us a brilliant demonstration as usual.

-I sense a touch of irony in your answer, my dear Guy, but I'm asking to see.

-I don't think you can both dispute the fact that to measure this membrane potential, two electrodes are inserted: one in the external milieu and one in the internal compartment of the cell. Nor can you dispute that the electrodes are themselves connected to the millivoltmeter by electrical and metallic conductors A bit like an electrochemical cell (Figure 1).

-Not even Guy can deny this statement based on a fact.

-Then you must necessarily admit that you electrically connect the external

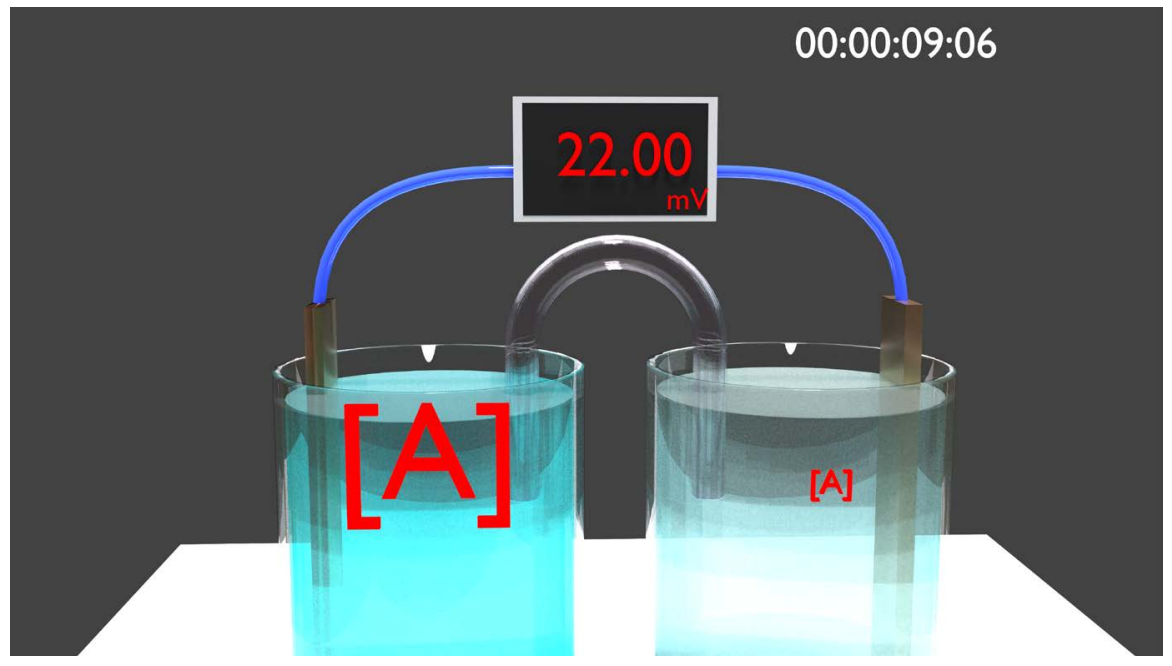

Figure 1. Example of an electrochemical cell. There is a potential because there are chemical reactions at the interfaces and the compartments are connected to each other by an external electric circuit and an ionic circuit is thus created in the electrolytes. 
milieu to the internal compartment by an external electrical circuit and thus create an internal ionic conductor within the system that connects the internal compartment and the external milieu. This ionic conductor exists only because there is an external electrical circuit and electrodes [1]

-You're telling us that by wanting to measure the membrane potential, the observers create a model and that the measured property depends only on what you want to observe, a bit like observing certain properties of quantum physics.

-That's right, Guy. You seem to be thinking, Jules?

-I'm indeed doubtful. Bernstein's model [2] is based on Nernst's equation, which does indeed belong to electrochemistry [3], but you've just told us that using an electrical device to check the validity of the model automatically leads to the appearance of an electrical property that might not belong to the real model (Figure 2).

-That's exactly right, Jules. Take a battery, for example; can you tell me its voltage?

-Your question is imprecise, but a common battery is $1.5 \mathrm{~V}$, right?

-No, because to measure its potential at time $t$, you have to establish an electrical circuit with a voltmeter that will induce an ionic movement in the battery and change its state, and at the same time make an electric current flow. When it is not connected, you have no way of knowing its tension and it is certainly higher than the one you are going to measure.

-When you're talking about greater, do you mean open-circuit voltage? ask Guy.

-Yes, that's it. It's always higher because the impedance of the load is infinite; there isn't actually any, but then you have to admit that the current flowing through it is always zero.

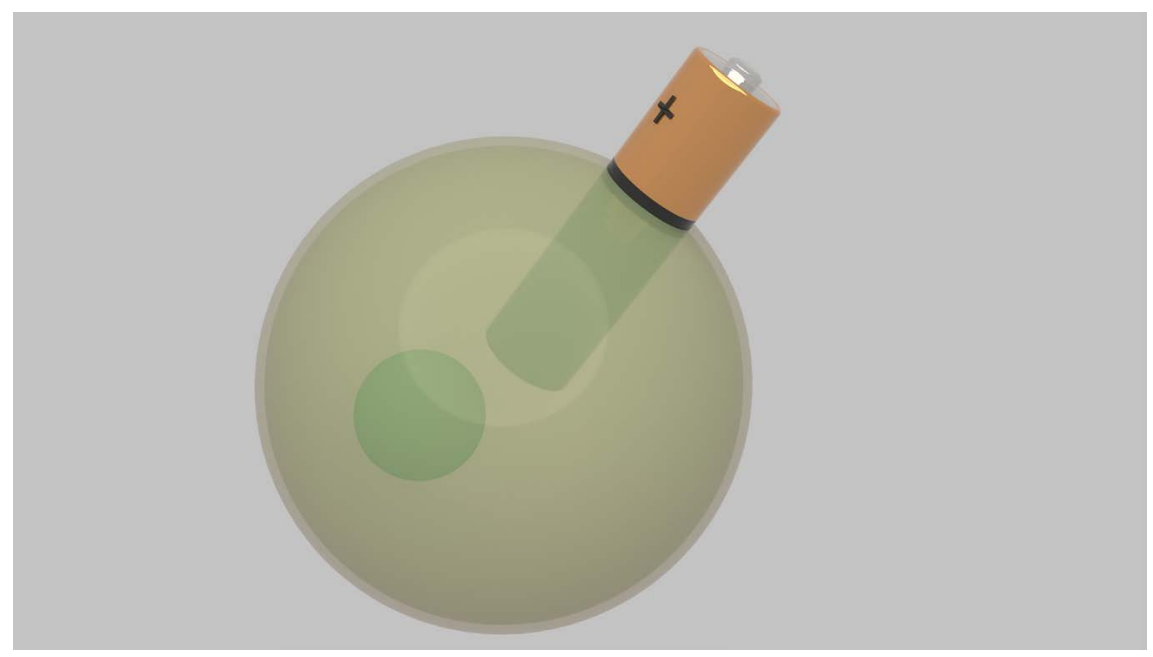

Figure 2. Example of a cell in a normal situation (artistic view showing the membrane potential). It has a membrane potential which is not measurable because the measuring devices are not electrically connected, the properties are no longer accessible but are not necessarily electrical. The forces involved are then only chemical, electrostatic, Coulombic and mechanical. 


\subsection{Steady State}

-This is like saying that the stationary state would not exist in the cell as a century of biology has taught us. You are denying the validity of the work of renowned scientists, most of whom have been awarded a Nobel Prize," says Jules.

-The validity of a theory can be crowned with a Nobel Prize, but the job of a scientist is often to criticize the theory and find a better one. On the contrary, I think that all these illustrious researchers were acting in good faith because they saw that certain problems such as junction potentials were affecting the observations. They based their work on the knowledge of the moment, but we are lucky to be able to review it with today's theory, which is normally better but always in motion.

-But the diffusion potential was demonstrated and measured by Nernst and Planck. Computations have proven the theory to be valid! asks Guy.

-But it is still true that the theory is linked to chemistry. Nernst was forced to use a luxury of precautions for his experiment and there is an electrical circuit because it is electrochemistry [4]. In addition, he had not been aware of Hofmeister's series, which applies in the case of cells because it contains peptides and various proteins.

-Well, I'll try to go your way, Walt. Let's pull the circuit breaker. What's going on? Jules imposes.

-I'll try to be clear: Nernst's equation does not describe a steady state or its establishment.

There's always a beginning and then a kind of equilibrium state with all the ions taken into account, positive and negative.

If there is indeed diffusion of positive ions it is because they are more mobile than the negative ones in this case and they will go to the less concentrated side because they are more abundant on the more concentrated side.

So initially both sides are electroneutral.

Then, little by little some positive ions go to the less concentrated side.

But this creates an electric field that opposes this movement.

A kind of equilibrium is reached when the field counteracts any ionic movement.

We can say that the system is somehow stiffening."

-You don't seem to like this stiffness? asks Guy.

-Exactly because it goes against what we know. It prevents any ion exchange and it is mono ionic. It excludes all the independence that biologists want. It is the fastest ion in terms of diffusion that will block the system. The blocking is total: the positive ions cannot leave the cell but they cannot enter it either. $\mathrm{Na} / \mathrm{K}$ pumps are then totally useless. In any case, the multi-diffusion model as taught remains highly questionable in any case.

\subsection{Ionic Independence}

-You also challenge the diffusion of several types of ions in an independent 
manner. Hille is not going to be your friend! [5] Jules replies.

-Science is not about friendship, but about facts and logic. Nernst and Planck have defined a very precise mono ionic model. This precision allowed them to simplify the equation because the initial conditions were known. A concentration gradient has a direction: it is a vector. The electric field induced by diffusion has itself a direction: it is also a vector. The two are intrinsically linked. The diffusion of a positive ion implies the direction of the electric field in the Nernst and Planck hypothesis [4]. There is no notion of direction in the initial equation because the conditions of its application were simple but logical.

-But couldn't we say that what is observed is the resultant of the contribution of each ionic species? says Guy.

-This is an interesting question: Some ions certainly act independently, and this action is simultaneous for all ions. But Nernst and Planck did not consider a case where diffusion occurs against a concentration gradient because this does not exist. It is not possible. The presence of an electric field imposes itself on all ions and they lose their independence of freedom of movement. There can only be one electric field and therefore diffusion is limited or even prevented. Ions cannot escape simultaneity and the notion of superposition, whereas the current theory, on the contrary, shows it in a sequential way.

-You even dispute the unquestionable, Walt! Boyle and Conway [6], Hodgkin [7] and many others have proven the validity of the ion diffusion theory. ironically Jules.

-Seriously, Jules, they have changed the concentrations of the solutions, but does that validate any diffusion theory? No, but it does change the flow of the electrochemical machine. And it doesn't change any of the objections that have already been raised and many more to come.

\subsection{Electrical Circuit}

-It's no longer a deconstruction of a model, it's a complete demolition! insists Guy.

-It is you who wanted this debate evening and we remain quite courteous. There is another aspect that I have a big problem with. It's this aspect of an electric circuit with these notions of batteries, capacitors and other resistors: it's very improbable as a hypothesis.

-You are insane: you are now challenging a lot of biophysics and electro-neurophysiology. Koch will be laughing his ass off! adds Jules. [8]

-You can't escape the laws of chemistry and electrochemistry. The proposed model is connected. This connection involves ionic circulation and therefore arbitrary electrical properties insofar as it is the instrumentation that will produce them. This electrical model is a technological feat that would make any electronic engineer dream, for sure.

You agree that resistors have one terminal in the extracellular milieu and another in the intracellular compartment. 
You have to accept that membrane batteries have in the same way one pole in the extracellular medium and another in the cell.

You must also accept that the capacitor has one terminal in the extracellular medium and another inside the cell (Figure 3).

-I don't see what's wrong with that description. It's the definition of the components that make up the classical electrical model. answers Jules.

-You have a faculty to close your eyes to the evidence, my dear Jules. If you accept this definition, then you are forced to connect all the terminals that have the same origin together. Try to connect a battery and the resistor in series as in the model we are taught!

-Hummmm, this is not possible because the components are connected in parallel with the definition you gave me: you must have made a mistake.

-Well...Try again and reread this definition carefully. And don't forget that the capacitor is pierced by the resistors that are the ion channels and I don't think the battery is ideal either. And I don't discuss the extraordinary dielectric of the membrane...

-Looks like... you're right. I can't explain these anomalies.

-It's more than just an anomaly and you can see it's not working in a very simple way anyway. It's a very basic and inexpensive circuit and then you plunge it into a bowl of salt water but be careful, it's a bit hazardous.

-I don't see the point, I'm pretty sure there's going to be a short circuit. Guy wonders.

-Almost certain... The first word is almost... too much.

In any case, if the circuit was really this one, then the voltage excursion is

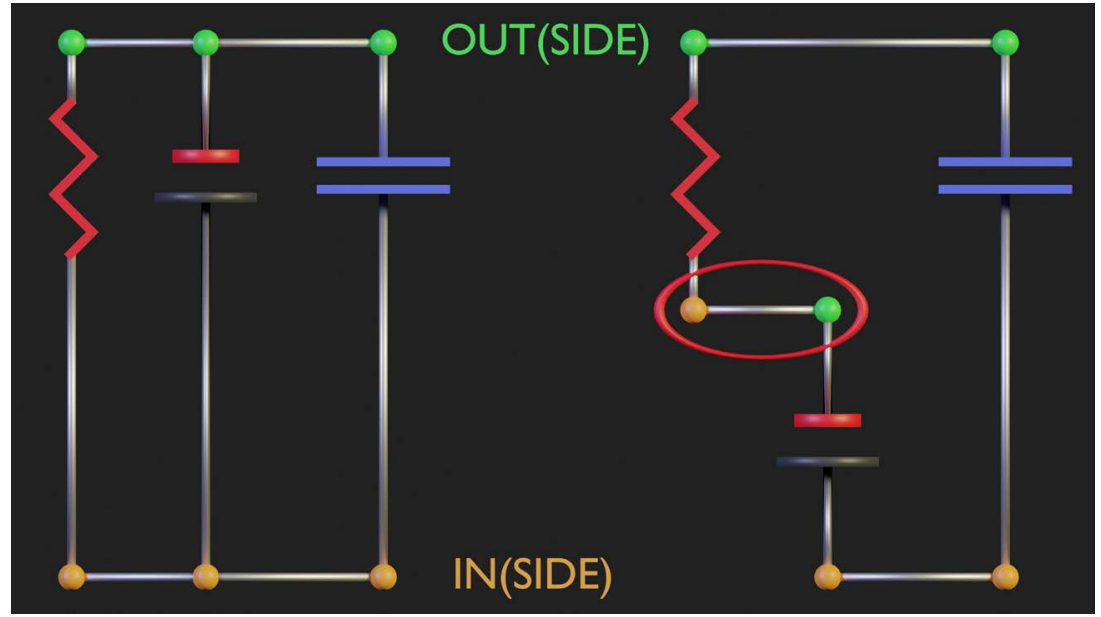

Figure 3. Comparison of electrical circuits. The circuit on the left is made and connected with the anatomical definitions and locations of the "electrical components": ions channels in red (resistance), membrane capacitance is marked in blue and the concentration's gradient creates the membrane potential. The model on the right is the famous $\mathrm{HH}$ model. There is a big problem because it connects components with wrong anatomical localization of some "terminals". Internal terminals are shown in orange where external are green. This leads to a short circuit (red circle) with all the consequences that can be expected. 
limited to the maximum value of the membrane battery and you see, Jules, I'm going to do the marine biologists proud. The electric eel is able to produce a potential of over $800 \mathrm{~V}$. This is only possible because the action potentials add up and to add up they cannot have a common terminal. They must be insulated from each other. This is the only way to make this summation. The electrocytes are teaching us a lesson, but do we want to learn? You can even do a little experiment at home with a few batteries: How to put them together electrically to obtain a voltage that is higher than the value of the batteries taken separately?

-I can answer the question about batteries," says Guy.

-Don't be afraid. Give us the benefit of your science.

-The answer's already in the question statement. All you have to do is put them in series and it's true then they no longer have a common reference.

-That's exactly right. A small example that definitively rules out the electrical model of the cell. But we already knew this from the recordings of the potentials of the nerve trunks. We knew it and yet our model excludes this hypothesis which has already been verified.

-I admit that you raise doubts in my certainties about the scientific foundations of biology. The edifice now seems to me to be wobbly. What about permeability and ion channels?" Jules worries.

\subsection{Permeability and Ionic Pumps}

-Don't push it, Jules. I can only observe that the puzzle is no longer assembling and that the same must be true with membrane permeability and the function of ion channels.

-Too late, but I have both good and bad news on that front.

Permeability was an innovative concept that would have explained the different ion activities. Their authors take potassium as a reference and give it a value of 1 . Hodgkin and Huxley (HH model) manages to demonstrate that sodium, for its part, must have a permeability of 0.01 for resting potential. It is also said that the famous $\mathrm{Na} / \mathrm{K}$ ion pump works permanently and makes $2 \mathrm{~K}^{+}$for $3 \mathrm{Na}^{+}$ enter the cell to maintain this same resting potential. Sorry Jules, but you have a problem.

-But these notions have been accepted and taught for decades. You can't just throw around a simple allegation without any proof! And besides, it's a resting value as you say, sodium permeability increases in action potential.

-I just gave you arguments but you don't make a connection. The permeability is exerted in the same way on each side of the membrane as the biologists wanted so we can say:

The potassium comes in and out easily because the permeability $P_{K}=1$.

Sodium, on the contrary, does not enter and leave easily because the permeability $P_{N a}=0.01$.

How do you exchange $3 \mathrm{Na}^{+}$that did not go in with $2 \mathrm{~K}^{+}$that cannot go out because of the existence of an electric field? Even without this last pitfall, the 
given permabilities contest the validity of this exchange: the ratio is not correct.

However, I give you a point about the action potential but the drawback is that I subtract it again because the model taught gives us an initial value for sodium identical to potassium, dixit Hodgkin and Huxley. You have to choose, either it's the same or 100 times lower. You can't have both answers at the same time.

-You're getting boring, I assure you, being right all the time.

-I, too, have a question about this permeability. It's purely mathematical and logical," says Guy.

It is said that Goldman's equation is only a variation of Nernst's and indeed, the addition of permeability is done on both the numerator and the denominator(see: About permeability). It is also said that permeability allows the membrane, as it were, to change the value of the potential. But then, it is also possible to reformulate this equation by saying that permeability can be eliminated in the same way in the numerator and denominator and thus conclude that whatever its value, permeability has no influence on the potential [9].

-I had noted this anomaly as well," Walt adds.

-You're both extremely sick people.

-I have another way of bringing it about," Walt replies.

-At this point, go to the end of your argument," says Jules.

-One of the ways often used to compute the value of this potential and the small number of ions involved in its generation is to estimate the number of ions leaving the cell.

-Yes, so what?

-Take an example where 10 potassium ions have left the cell and two cases; one case where the permeability is 1 and the other 0.1 . What is the potential in these two cases? (Figure 4)

-You're an asshole and you fooled me.

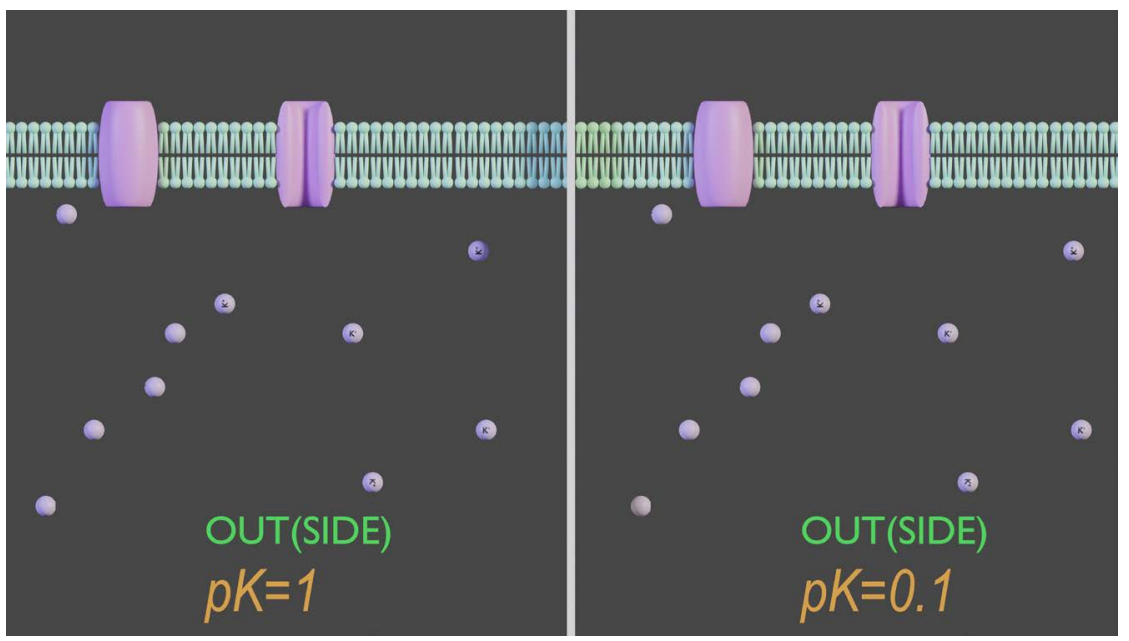

Figure 4. Permeability and charge imbalance. If there is a charge difference between the two sides of the membrane then the permeability has no influence on the potential difference. The computation remains the same and the permeability can in no way change the electrical value of the charge. 


\subsection{Ion Channels and Concentration Gradient}

-So what's the good news? asks Guy.

-It's about ion channels. Well, maybe it's not the good news you were expecting...

-I expect the worst!" ironizes Jules.

-You know me well. It is true that I must first point out a small mismatch.

You agree that most ion channels have a selective filter that arranges the ions in some sort of sequence.

-This is indeed the basis of the theory. Answer immediately Jules.

-Absolutely, there are even multiple hypotheses and types of sequences. adds Guy.

-You probably also agree that a membrane concentration profile is a diagram that gives the values of the different concentrations between the external and internal milieu of the cell. You admit that this same diagram, in the membrane the concentration evolves globally in a linear way between the external and internal concentrations.

-These are the very fundamentals of electrodiffusion according to NernstPlanck and, of course, Goldman, Hodgkin and Katz," says Jules.

-So, tell me what is the concentration in an ion channel since it is through this organelle that the transition between these two concentrations is made?

-Well... a value between the two extremes, obviously. recites Jules.

-You've learned your lesson well, but the sequences that are proposed reveal another truth. At best the ions follow a molecule of water and at worst they follow each other in single file [10]. These are extraordinary concentrations, to say the least (see: Membrane concentration profile).

-Does that mean you are challenging those assumptions, too?

-It would be easy to say that they are only hypotheses and that we do not yet have the technology to visualize and therefore verify such sequences, but no, they are extraordinary because they contain very little or no water. We must then assume and conclude that the concentration in the ion channel is immensely high and exceeds all the dilutions that we would be able to make in the laboratory. I'll spare you the computations but leave them for your analysis.

-So that's what I was saying: you rule out the possibility of diffusion because in the membrane the concentration is such that Nernst-Planck's theory is no longer valid," Jules admits (Figure 5).

-It is indeed a wall totally impenetrable to diffusion, but I will say that these ions, in single file, are not happy at all. They are restless and must be very thirsty.

-You're perfectly ridiculous! Now you're giving life to ions. Ironically Jules.

-Not as ridiculous as it sounds. I understand the metaphor. Ions attract water molecules and that creates a strong force if, as Walt says, the concentrations are such that the water seeks contact with the ions in the ion channel. But is this possible in this pore? 


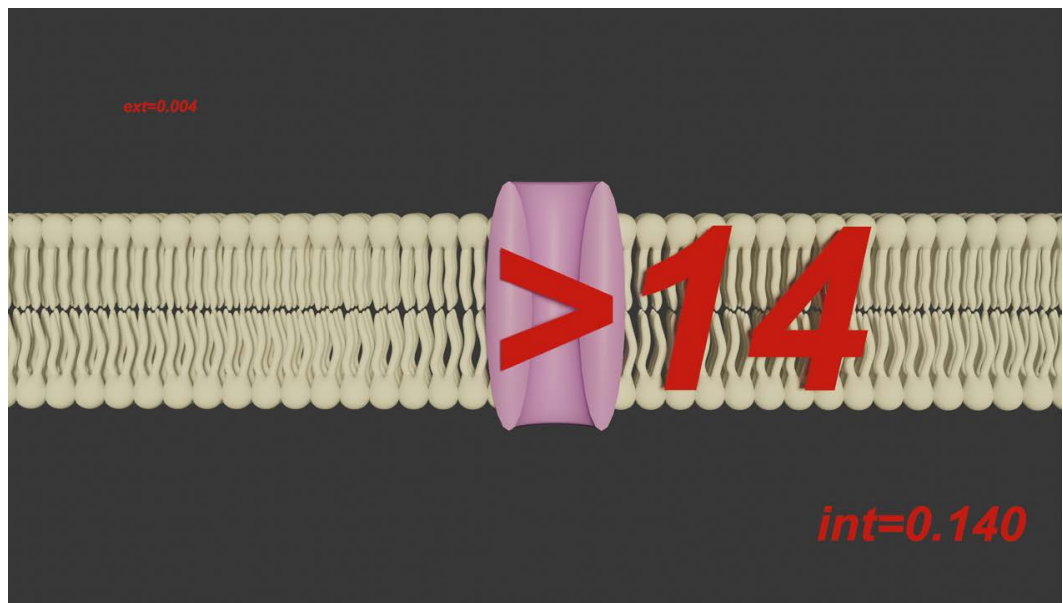

Figure 5. Membrane concentration profile. Considering the different concentrations present, the ion channel always has the highest concentration. Indeed, it is stated that diffusion takes place through these channels. In such a case, the membrane concentration profile shows that it is not possible for diffusion to take place as the theory would suggest. The concentration in the ion channel is at least 14 moles: such a concentration defies chemists and biologists.

-You got the idea, but I see something much more elegant, but I must admit that it's still marine biology that gave me quite a hand.

-Come on, don't leave us hanging! Admit Jules.

-Like I said, the arrangement of the ions in the filter is unusual. The ions tend to want to separate. Coulombic interactions are very important and are exerted in all directions as well as on the walls of the filter. I would tend to say that the retention of the physical structure of the ion channel itself is under severe strain. This must lead to a kind of elastic fluctuation and to a minimal vertical movement of the ions present in the filter. This movement could very well be recorded electrically.

-The theory would be that this signal would be that of the opening and closing of the channel. Jules intervenes.

-Let's go back to marine biology and its findings. Let me introduce you to the nematocyst [11] [12]. It's a highly specialized cell. It's what sea anemones, for example, use to harpoon their prey. The particularity of this cell is that the harpoon is folded inside the cell and unfolds when calcium ion channels are activated and their contents, calcium ions, enter the said cavity. And, of course, water enters by simple osmolarity in more than significant quantities and at such a speed that the harpoon is deployed. Ions, water and it's done. Simple, elegant and this system has been around for hundreds of millions of years.

-Okay, that's wonderful, but you're not telling us how they're activated. In the case of the neuron, the membrane depolarises, right? Guy tempers.

\subsection{Depolarization and Information}

-For once, I'm going to be the one with the critical eye. That phrase: "The membrane depolarizes" has always left me wondering. That sentence is the op- 
posite of scientific principles. No argument, no means and no theory. reject Jules.

-With all the elements that have been discussed, you might have an idea about this. Invite Walt.

-With what I've learned, a few ions that change location with a few more of water molecules are a perfectly presentable way to go.

-No better. But you're missing the why! You give the means: the ion and water molecule transport across the cell membrane, but for what purpose?

-Don't take me for a fool! The transduction and transfer of information. The mechanoreceptors are known. I suppose, logically, heat, pressure and other kinds of data can be transformed in this way.

-Far be it from me! I would just like to add to the system, the notions of robustness and redundancy. Robustness is the essential notion in the transmission of information. It is important that all information, unimportant, is discarded and not transmitted and it is important that all important information is always transmitted without distortion. However, unimportant information can become its opposite when it is repeated at a certain rate or if two stimuli are sufficiently close together. These are the notions of spatial and temporal summation. It should also be noted that the initiation of the message takes place either near the soma or at the periphery. It is unusual for the stimulus to take place on the axon itself, yet it is this mode of stimulation that is often studied.

-Here again, it must be understood that the study of the neuron and the action potential was not an easy thing with technology at the time. tempers Guy.

-Yes of course, but it is still true that spatial summation is described as the algebraic addition of potentials but without explaining the underlying phenomena, and the same is true for temporal summation. The only assertions remain depolarization and its opposite: hyperpolarization. If you establish a model based on cnidarians then you give it a dynamism and a theory that works for these sub-threshold potentials. If you deform the membrane by any means, you already get a potential variation, but if you force it to deform from the inside, then you force the ions contained in the ion channels to enter the cell. And if ions enter then water enters because the concentration of our ions is still extraordinary at that moment. So there can be a rapid pressure gradient which is countered by the elasticity of the membrane itself. It is even possible to add that some ion channels can be triggered by a potential. An ion is a potential when it becomes mobile. If the stimulus is not sufficient, then the water tends to come out through the effect of the elastic membrane and the recharging of the ion channels which will return to their initial shape. There is a return to a state of tension ready to be triggered again. It can be extrapolated that this recovery is slower than the active phase.

-It's hard for me to argue with that logic because you've already provided some evidence to that effect. Jules insists. But we're talking about local potentials that aren't being propagated. I understand the local distortion but I don't see 
how the signal is propagated!

-If you admit what has just been said then it's simple. You have to look at it in three dimensions. An axon is a kind of cylinder and a local stimulus will deform its surface at a specific point but the edges of that point will also be impacted. The entry of water is not evenly distributed under this surface, but the more ion channels are triggered and the larger the surface is, the larger the surface will be, to complete a whole circumference of the cylinder. You then have a volume with uniform and connected edges. It's a robust geometry that will be the vehicle for our message. The edge becomes active because its deformation causes the entry of ions and this entry pulls the water that is already present near the active edge. You create a suction on the opposite edge of the ring and this closes the ion channels of that edge. You get a self-sustained movement towards the active edge of the ring (Figure 6).

-The hypothesis is elegant and has a rationale that is difficult to contradict, but I still see a flaw in it: you don't talk much about a return to normal! asserts Guy.

-The hypothesis is certainly not complete but it already perfectly explains the refractory period. I admit that at the moment the return to normal remains a bit vague for me. admits Walt. But we've already made quite a bit of progress in the reconstruction of the world.

\subsection{The Problem of Electroneutrality}

-I have indeed learned a certain amount of new knowledge that now forms a more acceptable puzzle, but can I address a question about electroneutrality? asks Guy.

-I am cautious of Guy's questions. He's always looking for things that others haven't thought of.

-Although we have shown that this is unlikely, it is said that this membrane potential is the result of a charge difference between the inside and outside of the cell. In this case, an output of potassium ions. If this theoretical model was valid then it is also valid for all cells with exceptions of course.

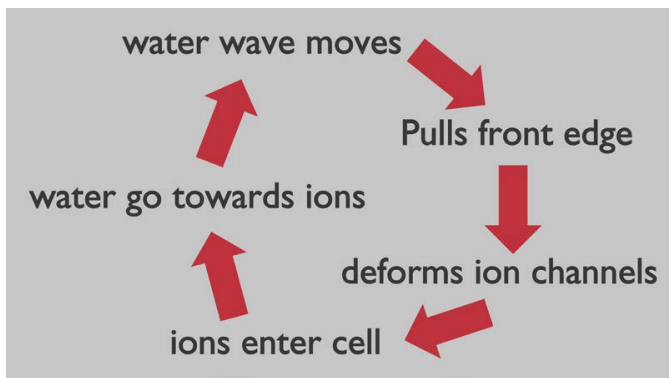

Figure 6. Action potential propagation cycle. Once the threshold is exceeded, the amount of water mobilized is sufficient to deform the membrane at the rising front of the action potential. The membrane is then stretched to deform the ion channels and allow the entry of ions. This results in a movement of water towards the incoming ions and a pressure drop at the falling front. The cycle is then repeated. 
-For once, Guy, your logic is flawless, but where does it all go? replies Jules.

-Well... I think this is the best proof that the model is not correct, Jules!

-You've had proof from the beginning the model doesn't work, but you've been waiting until almost the end of the night to let us know. It's the best one of the day! Jules ironizes.

-I find it so obvious that I don't understand how it could escape all the biologists. It's also the reason why I've been waiting. I thought you were going to find this evidence too, which is so logical!

-Okay, it seems, cautious indeed. Walt adds. So?

-You take a Hela cell and put it in a nutrient environment of known volume [13]. Logically you add $\$ \mathrm{~m} \$$ potassium ions to that solution. If the cell is dividing and this is still the case with the Hela stem then you must have 2 time $\$ \mathrm{~m} \$$ ions at the first division outside and so on. This logically, after a short time, forces us to be able to measure an increase in the concentration of potassium in the solution and also an increase in the potential difference with respect to the inner milieu of a reference cell (see: Electroneutrality violation).

-You have just buried all my certainties in a few sentences and there is nothing I can do about it. Bravo!" Jules yelps. But if we can avoid Hela, that would be a plus.

-Looks like the model has never been tested with an $n>1$. That's a pity! But our new model is even more robust because the electroneutrality is preserved in the external environment as well as in the internal compartment. Finally, it is a little more complicated for the internal environment... says Walt.

\subsection{Towards a Better Model}

-However, I think that my explanation, which is perfectly logical, has yet another consequence in my humble opinion. I'm willing to bet that the external concentration of potassium will decrease as the cells multiply and since the internal concentration of potassium is higher than the external, the cells will draw from this pool," Guy insists.

-Well found and this supports the studies of Conway, Hofmeister [14] [15] and especially Ling [16] [17]. confirms Walt.

-Regarding Conway's paper, it is surprising that Hodgkin, who refers to it, does not once appeal to his explanation. He downplays it to impose permeability. Conway, as Ling gives an explanation based on facts: potassium enters the cell because it contains proteins that bind it better than sodium, but I don't really understand why? asks Jules.

-Potassium is slightly more voluminous than sodium, but its valency is the same. It is therefore less electronegative than sodium. Proteins have receptor sites that are more friendly to potassium because sodium tends to bend proteins too much and that tends to reject it. explains Walt.

-As Boyle and Conway say, potassium enters the cell at the same time as protein. It's a kind of chemical and electrostatic fatality of some kind. Proteins act 
like magnets on potassium," Guy adds.

-Okay, but then it forces us to review almost all the mechanisms of ion inflow and outflow into the cell, the generation of membrane potential and the propagation of action potential. Facts have been observed but the theory to explain them does not seem valid. Others will have to be found but some already exist. reassures Jules.

-I think our model's not so bad already. There may be a missing explanation for the phase change of the membrane, but again Tasaki [18] and now Heimburg [19] are giving us facts and theories that bring new pieces to our puzzle and we have a solid foundation that holds together and complements each other harmoniously. adds Guy.

-There is still one missing piece to this model. It does not explain in any way the saltatory conduction, but this omission can also be filled by mechanical waves. We then have a simple extension of the basic mechanism that respects thermodynamics laws. It is indeed logical that the increase in speed of transmission of action potential can only be achieved at the expense of greater energy expenditure [20]. Moreover, you have a compressive phase which is followed by an expansion, which fits perfectly with the observed facts. concludes Walt.

\section{Annexes}

Table 1 shows the symbols and definitions used in this study.

\subsection{About Permeability}

The Goldman equation can be written in the following form for potassium, because it is a simple variation of the Nernst equation:

$$
E_{m}=\frac{R T}{z F} \ln \frac{P_{K}\left[K^{+}\right]_{\text {out }}}{P_{K}\left[K^{+}\right]_{\text {in }}}
$$

There are then an infinite number of $P_{K}$ values with $P_{K}>0$ that do not change the generated membrane potential in any way. It is indeed possible to

Table 1. Symbols \& definitions.

\begin{tabular}{cc}
\hline Symbols & Definitions \\
\hline$C$ & Capacitance \\
$R$ & electric charge \\
$T$ & universal gas constant \\
$Z$ & temperature \\
$F$ & ion valency \\
$E_{m}$ & Faraday constant \\
$P_{K}$ & membrane potential \\
$e$ & potassium permeability \\
\hline
\end{tabular}


simplify the equation to return to the Nernst equation.

$$
E_{m}=\frac{R T}{z F} \ln \frac{\left[K^{+}\right]_{o u t}}{\left[K^{+}\right]_{i n}}
$$

In addition, it is stated that the potential can be computed as the charge difference that exists between the inside and outside of the cell. This difference is in no way affected by permeability, since permeability does not change the valence of the ion, nor its charge.

Similarly, the permeability of one ion has no influence on the charge value of the other ions. This is a recognized principle in chemistry that is not disputed.

\subsection{Membrane Concentration Profile}

In the human body the concentration of potassium in the external cell environment $\left[K^{+}\right]_{o u t}$ is measured on average at 4 milli moles per litre.

The concentration of potassium in the internal cell compartment $\left[K^{+}\right]_{i n}$ is measured on average at 140 milli moles per litre.

It is expected by theory that the potassium concentration inside the membrane $\left[K^{+}\right]_{m e m b}$ should be between these two values.

$$
\left[K^{+}\right]_{\text {in }}>\left[K^{+}\right]_{\text {memb }}>\left[K^{+}\right]_{\text {out }}
$$

The concentration of pure water is calculated at 55.5 moles per litre.

The distance between the ions or water molecules inside the selective filter contained in the ion channels is about the same as the distance that naturally exists in a solution.

However, theory tells us that the ions follow each other in sequence in the selective filter. At worst, there is only one ion for 3 molecules of water and at best the filter contains 4 ions. These arrangements make it possible to compute a minimal concentration of 13.875 which excludes any possibility of diffusion through the ion channel!

$$
\begin{gathered}
{\left[K^{+}\right]_{\text {memb }}>\left[K^{+}\right]_{\text {in }}>\left[K^{+}\right]_{\text {out }}} \\
{\left[K^{+}\right]_{\text {memb }}>13.8 M l^{-1}}
\end{gathered}
$$

\subsection{Electroneutrality Violation}

The membrane potential assumes that there is a small electrical charge difference between the inside and the inside of the cell. The outer surface of the cell would have a small positive charge difference.

This small difference $\$ \mathrm{~m} \$$ is often estimated to be in the order of a few million elementary charges $e$.

It is therefore possible to say that the external environment contains $m$ more positive charges than the inside of the cell. This must also be true for each cell added to the external compartment.

It is then possible to say that if the external milieu contains $n$ cells then it con- 
tains $n$ time $m$ elementary charges $e$ for an ion of valence +1

This configuration excludes both the possibility that the membrane is a capacitor and also excludes the possibility of charges being distributed over the surface of the cell. If this were the case, the charge accumulated in the external environment would become dangerous but still measurable.

Our measurements of the external milieu remain hopelessly electroneutral and the only scientific conclusion to this mystery is that the external milieu does not contain $n$ time $m$ elementary charges $e$.

\section{Conclusions}

-"Guy can you give us a synthesis of our findings?” asks Jules.

-"We certainly need to engrave our interview in marble. We have the chance to get to know each other well, which has made it easier to keep an open mind, which is not always the case in real life," adds Guy.

The generation of membrane potential, the sustaining of this membrane potential, the action potential and its propagation as we know it form an empirical model based on the discoveries and deductions of illustrious scientists.

Nevertheless, the use of the law of Nernst and Planck cannot be used in this case. It is not possible to conceive of a two-way diffusion.

Diffusion cannot be a driving force for the generation and maintenance of membrane potential. If the ion channels are not disputed then they impose a membrane concentration profile that is outside the acceptable values for any possible diffusion.

Violation of electroneutrality is not possible because it prevents the model from functioning.

The model has a divergent and impossible functioning when the number of cells increases.

The permeability can in no way change the membrane potential. The use of electrical equipment leads to major changes in the possible actual functioning of the model. This equipment adds arbitrary and error-prone electrical properties. The resting potential, the initiation and propagation of action potential cannot be like an electrical circuit. Such an electrical circuit does not conform to the anatomical description of its components. Such a circuit cannot under any circumstances run in a saline environment.

However, it seems that almost all the elements necessary to build a more natural and especially more elegant model are already known and observed. It is indeed possible to have a perfectly functional model which finally respects the laws of thermodynamics and which calls upon known and validated foundations.

\section{Acknowledgements}

I warmly thank all the co-authors, Hirohisa Tamagawa and Vladimir Matveev for their encouragement and valuable help in the production of this article. We would also like to thank Vera Maura Fernandes de Lima for her interest in our 
work and her constant encouragement. Likewise, we thank Reinoud Maex who took the time to read this article and to point out certain errors and inaccuracies. Finally, we thank William Winlow for his kindness and the time he devoted to us.

\section{Conflicts of Interest}

The authors declare no conflicts of interest regarding the publication of this paper.

\section{References}

[1] Bockris, J.O. and Reddy, A.K.N. (1970) Modern Electrochemistry. Springer US, Boston. https://doi.org/10.1007/978-1-4615-7467-5

[2] Bernstein, J. and Tschermak, A. (1906) Untersuchungen zur Thermodynamik der bioelektrischen Ströme: Zweiter Teil Über die Natur der Kette des elektrischen Organs bei Torpedo. Pflüger, Archiv für die Gesammte Physiologie des Menschen und der Thiere, 112, 439-521. https://doi.org/10.1007/BF01676972

[3] Nernst, W. (2003) Begründung der Theoretischen Chemie: Neun Abhandlungen, 1889-1921, 1. Aufl. Verlag Harri Deutsch, Frankfurt am Main.

[4] Maex, R. (2017) On the Nernst-Planck Equation. JIN, 16, 73-91. https://doi.org/10.3233/JIN-170008

[5] Hille, B. (2001) Ion Channels of Excitable Membranes. 3rd Edition, Sinauer, Sunderland.

[6] Boyle, P.J. and Conway, E.J. (1941) Potassium Accumulation in Muscle and Associated Changes. The Journal of Physiology, 100, 1-63. https://doi.org/10.1113/jphysiol.1941.sp003922

[7] Hodgkin, A.L. and Horowicz, P. (1959) The Influence of Potassium and Chloride Ions on the Membrane Potential of Single Muscle Fibres. The Journal of Physiology, 148, 127-160. https://doi.org/10.1113/jphysiol.1959.sp006278

[8] Koch, C. and Segev, I. (1998) Methods in Neuronal Modeling: From Ions to Networks. 2nd Edition, MIT Press, Cambridge.

[9] Goldman, D.E. (1943) Potential, Impedance, and Rectification in Membranes. The Journal of General Physiology, 27, 37-60. https://doi.org/10.1085/jgp.27.1.37

[10] Gouaux, E. and Mackinnon, R. (2005) Principles of Selective Ion Transport in Channels and Pumps. Science (New York, N.Y.), 310, 1461-1465. https://doi.org/10.1126/science.1113666

[11] Özbek, S., Balasubramanian, P.G. and Holstein, T.W. (2009) Cnidocyst Structure and the Biomechanics of Discharge. Toxicon, 54, 1038-1045.

https://doi.org/10.1016/j.toxicon.2009.03.006

[12] Lubbock, R., Gupta, B.L. and Hall, T.A. (1981) Novel Role of Calcium in Exocytosis: Mechanism of Nematocyst Discharge as Shown by X-Ray Microanalysis. Proceedings of the National Academy of Sciences, 78, 3624-3628. https://doi.org/10.1073/pnas.78.6.3624

[13] Lucey, B.P., Nelson-Rees, W.A. and Hutchins, G.M. (2009) Henrietta Lacks, HeLa Cells, and Cell Culture Contamination. Archives of Pathology \& Laboratory Medicine, 133, 1463-1467.

[14] Hofmeister, F. (1888) Zur Lehre von der Wirkung der Salze: Zweite Mittheilung. Archiv für experimentelle Pathologie und Pharmakologie, 24, 247-260. 
https://doi.org/10.1007/BF01918191

[15] Bye, J.W. and Falconer, R.J. (2015) A Study of the Relationship between Water and Anions of the Hofmeister Series Using Pressure Perturbation Calorimetry. Physical Chemistry Chemical Physics, 17, 14130-14137. https://doi.org/10.1039/C5CP00571J

[16] Ling, G.N. (1992) A Revolution in the Physiology of the Living Cell. Original Edition, Krieger Pub. Co., Malabar.

[17] Tamagawa, H. and Morita, S. (2014) Membrane Potential Generated by Ion Adsorption. Membranes, 4, 257-274. https://doi.org/10.3390/membranes4020257

[18] Tasaki, I. and Iwasa, K. (1980) Swelling of Nerve Fibers during Action Potentials. Upsala Journal of Medical Sciences, 85, 211-215. https://doi.org/10.3109/03009738009179190

[19] Heimburg, T. (2007) Thermal Biophysics of Membranes. Wiley-VCH Verlag, Weinheim. https://doi.org/10.1002/9783527611591

[20] Delalande, B., Tamagawa, H. and Matveev, V. (2019) Another Train Paradox/May the Myelin Be with You! 